\title{
Perfiles aerodinámicos Joukovsky notas suplementarias de aerodinámica
}

Joukowski airfoils supplementary notes to aerodynamics

\section{Luis A. Arriola ${ }^{\mathrm{I}}$}

1 Aerospace Engineer, M.S. Correo: larriolag@usmp.pe Facultad de Ingeniería y Arquitectura, Escuela Profesional de Ciencias Aeronáuticas, Universidad de San Martín de Porres, Lima Perú

\begin{abstract}
Mapping a cylinder into a Joukowski airfoil, takes several geometric steps that have to be carefully considered. By doing this, the velocity around the cylinder has to be related to the velocity at the surface of the airfoil. Once the velocity at the surface of the airfoil has been determined, the pressure distribution on the airfoil can be obtained using the pressure coefficient. Moreover, the value of the Circulation $\Gamma$ must be obtained from Kutta's condition. According to this condition, the flow must leave the trailing edge smoothly and because of this, the velocity components on the trailing edge which are a function of $\Gamma$ are equal to zero. Solving this equation equal to zero becomes easy when we determine the circulation $\Gamma$. Hence, by using the Kutta-Joukowski theorem and the circulation that has been previously found, the lift can be determined. Then, the lift coefficient can be found as well.
\end{abstract}

Keywords: Joukowski airfoil, airfoil, pressure distribution, pressure coefficient, Circulation, Kutta's condition, trailing edge, Kutta-Joukowski theorem, lift, lift coefficient

\section{Resumen}

Levantando el plano de un cilindro al plano de un perfil aerodinámico Joukowski, lleva varios pasos geométricos que tienen que ser considerados cuidadosamente. $\mathrm{Al}$ realizar esto, la velocidad alrededor del cilindro tiene que estar relacionada con la velocidad en la superficie de sustentación del perfil aerodinámico. Una vez que la velocidad de este último haya sido determinada, la distribución de presión sobre la superficie de sustentación se puede obtener por medio del coeficiente de presión. Además, el valor de la circulación $\Gamma$ se debe obtener de la condición de Kutta. De acuerdo con esta condición, el flujo debe dejar el borde de fuga suavemente, y debido a esto, los componentes de la velocidad en el borde de fuga que son una función de $\Gamma$ son cero. Resolver esta ecuación que es igual a cero resulta fácil al determinar la circulación $\Gamma$. Por lo tanto, considerando el teorema de Kutta-Joukowski y la circulación previamente determinada, la sustentación puede ser encontrada y, entonces también, el coeficiente de sustentación $\mathrm{Cl}$ puede ser hallado.

Palabras clave: perfil aerodinámico, Joukowski, superficie de sustentación, distribución de presión, coeficiente de presión, circulación, condición de Kutta, borde de fuga, teorema de Kutta-Joukowski, sustentación, coeficiente de sustentación 


\section{Introduction}

One of the major results obtained in Aerodynamics is the calculation of the ideal flow past a cylinder. Because we do not see flying cylinders, you may wonder why this result is so important. Two reasons will be given here. The cylinder has a simple shape and can be easily tested in a wind tunnel to determine the limitations of ideal fluid theory. Moreover, the cylinder can be mapped into arbitrary shapes by using appropriate mapping functions. This allows us to determine the velocity and the pressure distribution on a body of arbitrary shape.

\section{Discussion}

These notes will describe the procedure that maps a cylinder into an airfoil. As an illustration, a Joukowski airfoil will be considered. Before we do this, we need to review some results relevant to flow past cylinders.

If the origin of the coordinates coincides with the origin of a cylinder of radius R, then the stream function, $\Psi$, or potential function, $\Phi$, as described by Bertin and Smith (1998) for a lifting cylinder can be obtained by superimposing a uniform flow in the $\mathrm{x}$-direction, a doublet at the origin whose strength is:

$$
\hat{\mathrm{A}}=\mathrm{R}^{2} \mathrm{U}_{\infty}
$$

and a vortex at the origin of strength $\Gamma$ (gamma). The result can be written as:

$$
\Psi=\mathrm{U}_{\infty}\left[1-\frac{\mathrm{R}^{2}}{\mathrm{r}^{2}}\right] \mathrm{r} \sin \theta+\frac{\Gamma}{2 \pi} \ln \left(\frac{\mathrm{r}}{\mathrm{R}}\right)
$$

and

$$
\phi=\mathrm{U}_{\infty}\left[1+\frac{\mathrm{R}^{2}}{\mathrm{r}^{2}}\right] \mathrm{r} \cos \theta-\frac{\Gamma \theta}{2 \pi}
$$

As a first step in achieving our goal, let us determine the stream function for a cylinder whose center is not at the origin of coordinates and whose angle of attack $\alpha$ is different from zero.

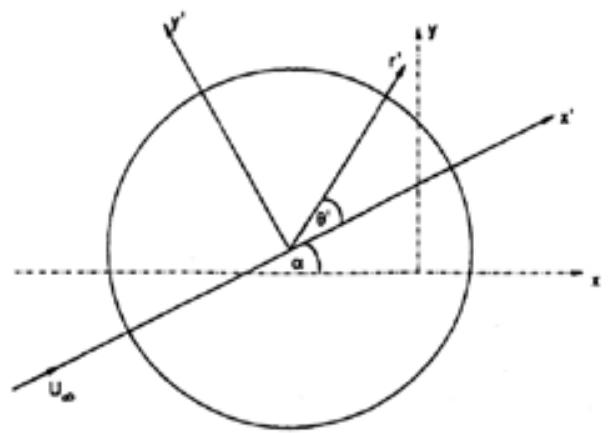

Figure 1. Schematic of a Cylinder

Figure 1 shows such a cylinder. Note that the $x^{\prime}$-coordinate is the direction of the freestream velocity and y' is normal to the freestream direction. The angle between the coordinate axes $x x^{\prime}$ is the angle of attack $\alpha$. We can write the stream function in terms of the coordinate $\left(x^{\prime}, y^{\prime}\right)$ using equation 2 . The result can be written as:

$\Psi=\mathrm{U}_{\infty}\left[1-\frac{\mathrm{R}^{2}}{\mathrm{r}^{\prime 2}}\right] \mathrm{r}^{\prime} \sin \theta^{\prime}+\frac{\Gamma}{2 \pi} \ln \left(\frac{\mathrm{r}^{\prime}}{\mathrm{R}}\right)$

To determine $\Psi=\Psi(x, y)$, we have to determine the relationship between ( $x^{\prime}$, $\left.y^{\prime}\right)$ and $(x, y)$. To accomplish this, let us introduce the coordinate system $\left(x^{\prime \prime}, y^{\prime \prime}\right.$ ) whose origin coincides with the center of the cylinder but is parallel to $(x, y)$.

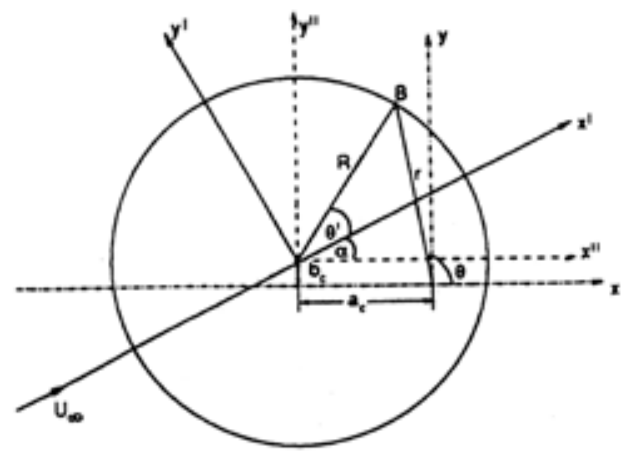

Figure 2. Relationship between $\left(\mathrm{x}^{\prime}, \mathrm{y}^{\prime}\right)$ and $(\mathrm{x}, \mathrm{y})$

It is noted from Figure 2 that

$$
x=x^{\prime \prime}-a_{c}, \quad y=y^{\prime \prime}+b_{c}
$$


where are the coordinates at the center of the cylinder. Again, we see from Figure 2 that:

$$
\begin{gathered}
x^{\prime}=x^{\prime \prime} \cos \alpha+y^{\prime \prime} \sin \alpha \\
y^{\prime}=\left|-x^{\prime \prime} \sin \alpha\right|+y^{\prime \prime} \cos \alpha
\end{gathered}
$$

Combining (5) and (6) yields the desired relationship, i.e.

$$
\begin{gathered}
x^{\prime}=\left(x+a_{c}\right) \cos \alpha+\left(y-b_{c}\right) \sin \alpha \\
y^{\prime}=\left|-\left(x+a_{c}\right) \sin \alpha\right|+\left(y-b_{c}\right) \cos \alpha
\end{gathered}
$$

Moreover, we can relate $\theta$ and $\theta^{\prime}$ by writing the coordinate of any arbitrary point $\mathrm{B}$ on the cylinder as:

$$
R \sin \left(\theta^{\prime}+\alpha\right)=r \sin \theta-b_{c}
$$

Now, if we substitute for $x^{\prime}, y^{\prime}$ into equation 4, we can determine $\Psi=\Psi(x, y)$.

This gives the stream function for a flow past a cylinder whose center is not at the origin and whose angle of attack is $\alpha$.

\section{Joukowski Transformation}

Now we are ready to talk about mapping. As can be seen from Figure 3, the equation of the circle under consideration can be written as:

$$
R^{2}=l^{2}+r^{2}+(2 l r) \cos (\theta+\delta)
$$

with

$$
l^{2}=b_{c}{ }^{2}+a_{c}{ }^{2}, \quad \tan \delta=b_{c} / a_{c}
$$

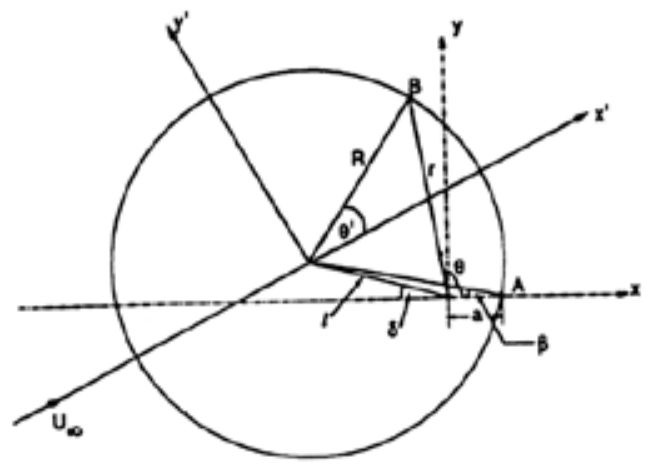

Figure 3. Schematic of a Circle
The Joukowski transformation that transforms equation 9 into an airfoil can be written as:

$$
x_{1}=x\left(1+\frac{a^{2}}{r^{2}}\right), \quad y_{1}=y\left(1-\frac{a^{2}}{r^{2}}\right)
$$

The resulting shape is shown schematically in Figure 4. The actual shape is calculated as follows:

The point A (Figure 3), which has the coordinate

$$
r=a, \quad \theta=0
$$

maps into the trailing edge of the airfoil. Substituting equation 12 into equation 11 yields the coordinate of the trailing edge as:

$$
x_{1}=2 a, \quad y_{1}=0
$$

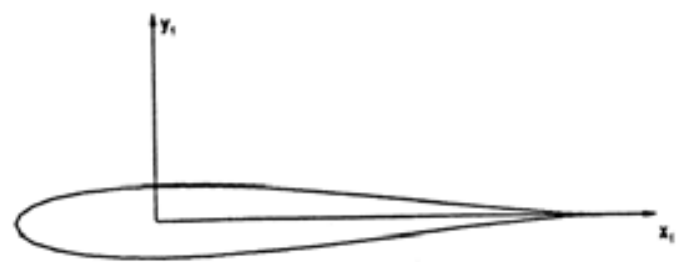

Figure 4. Schematic of a Joukowski Airfoil

Next (theta) is stepped from 0 to $2 \pi$ using, say, $5^{\circ}$ intervals. For a given theta, equation 9 gives $r=r(\theta)$ and since

$$
x=r \cos \theta, \quad y=r \sin \theta
$$

$x_{1}, y_{1}$ follow from Equation 11. Repeating the process will allow us to generate the desired shape.

\section{Determination of the Circulation}

Although we were able to relate the strength of the doublet to the radius of the circle and the free stream velocity, nothing was said, so far, about $\Gamma$. Obviously, we need to determine $\Gamma$ if we hope to calculate the velocity and the pressure distribution over the airfoil. The value of $\Gamma$ is determined from Kutta's condition. According to this condition, the flow must leave the trailing 
edge smoothly as described by Anderson, Jr (1989). This, in turn, requires the point A on the cylinder, which maps into the trailing edge, to be a stagnation point. This condition prevents the flow from turning around the trailing edge and insures the continuity of the pressure at the trailing edge. The implications of $\mathrm{A}$ being a stagnation point follows from calculating the velocities at A. If we consider the $\left(x^{\prime}, y^{\prime}\right)$ coordinate system (see Figure 3), then the point A has the coordinates:

$$
r^{\prime}=R, \quad \theta^{\prime}=-(\alpha+\beta)
$$

The velocity components are:

$$
\begin{gathered}
U^{\prime}(\theta)=-\frac{\partial \Psi}{\partial r^{\prime}}=-\left[\mathrm{U}_{\infty}\left(1+\frac{\mathrm{R}^{2}}{\mathrm{r}^{\prime 2}}\right) \sin \theta^{\prime}+\frac{\Gamma}{2 \pi r^{\prime}}\right] \\
U^{\prime}(r)=\frac{1 \partial \Psi}{r^{\prime} \partial \theta^{\prime}}=\mathrm{U}_{\infty}\left(1-\frac{\mathrm{R}^{2}}{\mathrm{r}^{\prime 2}}\right) \cos \theta^{\prime}
\end{gathered}
$$

For the conditions indicated in equation (14), equation (15) and equation (16) become

$U_{r}^{\prime}=0, \quad U_{\theta}^{\prime}=0=-\left[-2 \mathrm{U}_{\infty} \sin (\alpha+\beta)+\frac{\Gamma}{2 \pi R}\right]$

equation (17) yields

$$
\Gamma=2\left(2 \pi R U_{\infty} \sin (\alpha+\beta)\right)
$$

Now, using the Kutta-Joukowski theorem described in Bertin and Smith (1998), the lift can be determined as:

$$
L=\rho U_{\infty} \Gamma=4 \pi \rho\left(U_{\infty}\right)^{2} \mathrm{R} \sin (\alpha+\beta)
$$

For typical airfoils as, $a_{c}, b_{c}$ are small. Because of this, $\beta$ is a small angle and the chord of the airfoil can be approximated as [see equation 13]:

$$
c \approx 4 R
$$

As a result, the lift coefficient $C_{l}$ defined by Anderson, Jr. (1989) can be expressed as:

$$
C_{l}=\frac{L}{\frac{1}{2} \rho U_{\infty}^{2} c}=2 \pi \sin (\alpha+\beta)
$$

Usually, the flow separates at high angles of attack. Therefore, $\alpha$ should remain a small angle if the above theory is to remain valid. This allows as setting:

$$
\sin (\alpha+\beta) \approx(\alpha+\beta)
$$

and as a result we have

$$
C_{l}=2 \pi(\alpha+\beta)
$$

For symmetric airfoils,

$$
b_{c}=0
$$

which gives

$$
\beta=0
$$

and the lift coefficient for a symmetric airfoil reduces to:

$$
C_{l}=2 \pi \alpha
$$

\section{Pressure Distribution on the Airfoil}

The pressure distribution follows from Bernoulli's equation being defined by Anderson, Jr. (1989) as

$$
P_{a}+\frac{1}{2} \rho\left(U_{a}\right)^{2}=P_{\infty}+\frac{1}{2} \rho\left(U_{\infty}\right)^{2}
$$

where subscript" $a$ " designates an airfoil. The pressure coefficient defined by Bertin and Smith (1998) is

$$
C_{p}=\frac{P_{a}-P_{\infty}}{\frac{1}{2} \rho U_{\infty}^{2}}=1-\left(\frac{U_{a}}{U_{\infty}}\right)^{2}
$$

Thus, we need to determine the velocity on the airfoil surface. This will be accomplished by relating the velocity at the airfoil surface to the velocity $U_{c}$ at the cylinder. The relationship follows from

$$
\Gamma=\int U_{a} d S_{a}=\int U_{c} d S_{c}
$$

or

$$
U_{a}=U_{c}\left(\frac{d S_{c}}{d S_{a}}\right)
$$


where $d S_{a}$ and $d S_{c}$ are arc lengths around the airfoil and the cylinder respectively. Now

$$
\begin{aligned}
& d S_{c}=\sqrt{(d x)^{2}+(d y)^{2}} ; \\
& d S_{a}=\sqrt{\left(d x_{1}\right)^{2}+\left(d y_{1}\right)^{2}}
\end{aligned}
$$

The relationship between $\left(x_{1}, y_{1}\right)$ y $(x, y)$ is given by equation 11 . equation 11 gives

$$
\begin{aligned}
& d x_{1}=d x\left(1+\frac{a^{2}}{r^{2}}\right)-2 x \frac{a^{2}}{r^{4}}(x d x+y d y) \\
& =d x\left[1+\frac{a^{2}}{r^{2}}\left(y^{2}-x^{2}\right)\right]-2 x y \frac{a^{2}}{r^{4}} d y
\end{aligned}
$$

since

$$
\begin{aligned}
x & =r \cos \theta, \quad y=r \sin \theta \\
d x_{1} & =d x\left[1-\frac{a^{2}}{r^{2}} \cos 2 \theta\right]-\sin 2 \theta \frac{a^{2}}{r^{2}} d y
\end{aligned}
$$

Similarly

$d y_{1}=d y\left[1-\frac{a^{2}}{r^{2}} \cos 2 \theta\right]+\sin 2 \theta \frac{a^{2}}{r^{2}} d x$

Therefore

$$
d S_{a}^{2}=\left[\left(1-\frac{a^{2}}{r^{2}} \cos 2 \theta\right)^{2}+\left(\frac{a^{2}}{r^{2}} \sin 2 \theta\right)^{2}\right] d S_{c}{ }^{2}
$$

or

$$
\frac{d S_{a}}{d S_{c}}=\left[1-2 \frac{a^{2}}{r^{2}} \cos 2 \theta+\left(\frac{a^{2}}{r^{2}}\right)^{2}\right]^{1 / 2}
$$

$U c$ follows from Eq. (4) as

$$
U_{c}=U_{\theta}^{\prime}=-\left[2 U_{\infty} \sin \theta^{\prime}+\frac{\Gamma}{2 \pi R}\right]
$$

with $\theta^{\prime}$ given by Eq. (8), i.e.

$$
\theta^{\prime}=\sin \theta^{-1}\left[\frac{r \sin \theta-b_{c}}{R}\right]-a
$$

Equation 26, 31 and 32 give $U a$ and $C p$ follows from equation 25 . Note that the range of $\theta^{\prime}$ is from 0 to $2 \pi$.

\section{Conclusion}

We can determine the velocity on the airfoil surface and the pressure distribution over the airfoil just by knowing the velocity at the cylinder. Consequently, the lift can be determined too and so, the lift coefficient $C_{l}$. However, this can be done if we map a cylinder into a Joukowski airfoil correctly. The method presented here, is an alternative of such a procedure that reduces other complicated mathematical calculations such as the usage of complex numbers.

\section{References}

Anderson, Jr, J.D. (1989). Introduction to Flight (Third Edition) New York: McGraw Hill.
Bertin, J.J., \& Smith, M.L. (1998). Aerodynamics for Engineers (Third Edition). New Jersey: Prentice Hall. 
